\title{
GPS-TEC observations over Nepal during the Total Solar Eclipse on 22 July 2009
}

\section{A. N. Shrestha and Y. Migoya-Orue}

Journal of Nepal Physical Society

Volume 7, Issue 1, April 2021

(Special Issue: ANPA Conference, 2020)

ISSN: 2392-473X (Print), 2738-9537(Online)

\section{Editors:}

Dr. Santosh KC

San Jose State University, USA (Editor in Chief)

Dr. Pashupati Dhakal

Thomas Jefferson National Accelerator Facility, USA Dr. Yadav Pandit

Baptist Health Science University, USA

\section{Managing Editor:}

Dr. Binod Adhikari

St. Xavier's College, Kathmandu, Nepal

JNPS, 7 (1), 54-59 (2021)

DOI: http://doi.org/10.3126/jnphyssoc.v7i1.36976

Published by:

Nepal Physical Society

P.O. Box: 2934

Tri-Chandra Campus

Kathmandu, Nepal

Email: npseditor@gmail.com

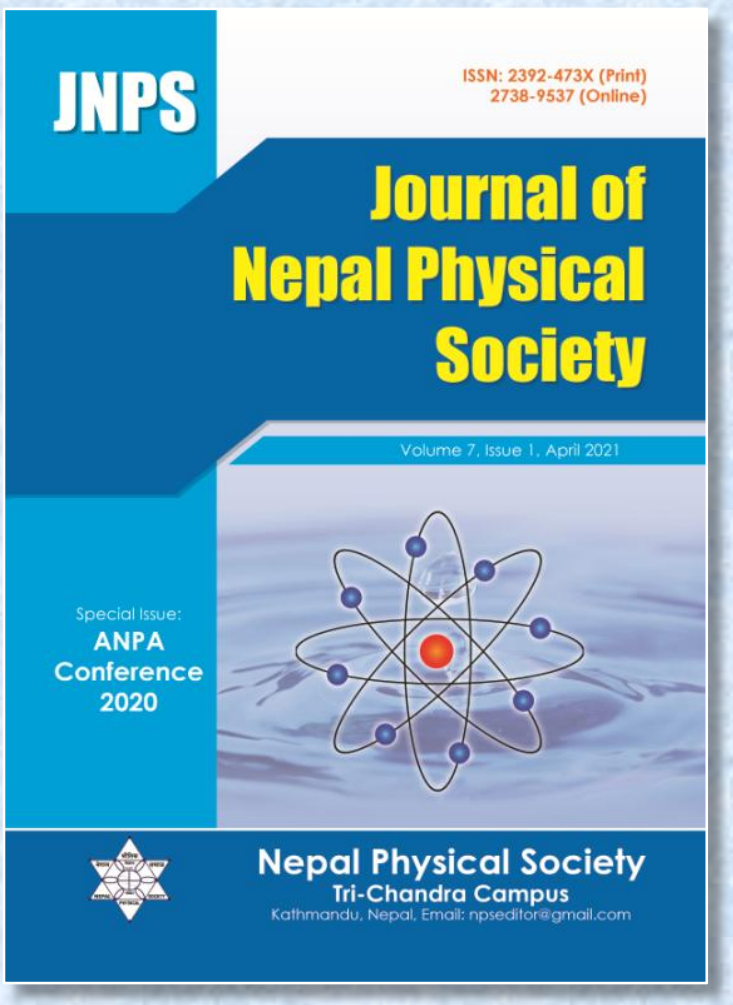




\title{
GPS-TEC observations over Nepal during the Total Solar Eclipse on 22 July 2009
}

\author{
A. N. Shrestha ${ }^{1, *}$ and Y. Migoya-Orue ${ }^{2}$ \\ ${ }^{1}$ Department of Physics, Amrit Campus, Kathmandu, Nepal \\ ${ }^{2}$ The Abdus Salam International Centre for Theoretical Physics (ICTP), Trieste, Italy \\ *Corresponding Email: shresthaagrima53@gmail.com
}

Received: 10 August, 2020; Revised: 22 January, 2021; Accepted: 8 February, 2021

\begin{abstract}
This paper explores the ionospheric response in terms of Total Electron Content (TEC) during the 22 July 2009 Total Solar Eclipse. Using the data stored at Biratnagar (BRN2), Ramite (RMTE), Dhangadhi (DNGD), Nepalganj (NPGJ), and Taplejung (TPLJ) Global Positioning System (GPS) stations, the ionospheric activity was investigated through changes in TEC. Our research is based on GPS-TEC measurements from a widely dispersed GPS network across various geographical locations in Nepal, taking place on July 17-21 as a pre-event, July 22 as the main event, and July $23-27$ as a post-event. The analysis reveals that the reduction in the TEC level is proportional to the magnitude of the total solar eclipse. The variation of the TEC depends on latitude as well as longitude. We found that TEC depletion was up to $5 \%$ from preevent to main-event and up to $30 \%$ from main-event to post-event during the totality of the eclipse. The eclipse was accompanied by the 10-hour geomagnetic storm in Nepal, which was the explanation for the TEC upgrade to $50 \%$ on the main event day from pre-event and decreased by $25 \%$ from main-event to post-event. The result obtained in this work demonstrates the influence of the eclipse/storm on the variation of TEC.
\end{abstract}

Keywords: Ionospheric total electron content, Total Solar Eclipse, Global Positioning System, Geomagnetic storm.

\section{INTRODUCTION}

A total solar eclipse occurs when the new moon occults between Sun and Earth and cast its umbra on Earth. It causes photochemical activity in the ionosphere to reduce to the extent observed during the night. It leads to a decrease in the value of the electron density in the ionosphere's E-layer and F1layer along with the total electron content (TEC), which is the electron density function [1,2].

On the morning of 22 July 2009, a total solar eclipse occurred in East and South Asia with a length of 6 minutes 39 seconds, followed by a moderate 10-hour geomagnetic storm. It is the longest solar eclipse of the 21 st century. There is a decrease in TEC due to the solar eclipse that has been studied by various techniques $[2,3]$, such as measurements derived from the Global Positioning System (GPS). GPS is a tool with the highest accuracy to study the ionosphere dynamics with varying TEC during the eclipse/storm period. TEC relies heavily on latitude, longitude, local time, and various solar and geophysical phenomena such as solar flares, geomagnetic storms [4,5]. During the solar cycle, the solar wind shock wave and the cloud of a magnetic field interacting with the Earth's magnetic field cause a deterioration of the Earth's magnetosphere called a geomagnetic storm. Several literature studies $[5,6,7]$ indicate that prompt electrical field penetration is eastward during the daytime and increases the electrical field dynamo effect, leading to increased vertical $E \times B$ plasma drift from lower to higher altitude, resulting in increased electron density in the day-side sector while TEC depletion in the night-side sector [8]. There is a separate latitudinal dependency in the TEC variation due to the solar eclipse [2]. Salah et al., 1986 [9], Kumar et al., 2013 [10], and Le et al., 2009 [4] record a decrease in TEC at a lower 
latitude (below the F1 layer). The Fountain effect is achieved by the decrease in the $\mathrm{E} \times \mathrm{B}$ plasma drift at low latitudes, and the strength of the Fountain effect will weaken when a solar eclipse occurs. As a result, the electron transport process will also decrease at low latitudes, which induces a decrease in TEC value in the low latitude region $[8,11]$. And the longitude depends on local time, being equal to 1-hour local time with $15^{\circ}$ longitude. The impact of an eclipse with varying longitude was studied by Krankowski et al., 2008 [12].

The impact of a total solar eclipse accompanied by a storm on TEC before, during, and after the occurrence of the eclipse on 22 July 2009 is examined in this report. GPS-derived observations from five stations around Nepal were collected using TEQC software from a non-profit universitygoverned consortium (UNAVCO) data center (website: http://www.unavco.org/). The obtained results demonstrate the effect of solar eclipse and storm on TEC variation on ionosphere-dynamics.

\section{DATA AND METHOD OF ANALYSIS}

In this research, ground-based GPS receivers were used at five stations in Nepal to observe the ionospheric solar eclipse and the magnetic storm effect after the solar eclipse on TEC variation. The variation of the TEC value was reported by taking into account the time of the total solar eclipse; 22 July 2009 as the main event, 17-21 July as the preevent, and 23-27 July as the post-event, respectively. Just two stations (BRN2 and RMTE) have witnessed eclipse totality, and the remaining three stations have partial solar eclipse (DNGD, NPGJ, and TPLJ).

The UNAVCO Data Center handles data management tasks for GPS/GNSS data and products from globally distributed permanent stations [3]. TEQC is the program developed by UNAVCO and supports several GPS tasks that translate to quality control of RINEX and GPS and a calibration method used to obtain TEC. The process of calibrating TEC is quite similar to the methods used by Ya'acob and Ismail (1990) [13]. GPS observation data collected for the five stations in Nepal [Table 1]. To research the eclipse/storm effect on the TEC variation during the time of the solar eclipse followed by a moderate storm, the TEC recorded with a time resolution of 15 seconds, which later converted to a minute resolution. The GPS data was recorded in universal time (U.T.+5:45=L.T.).

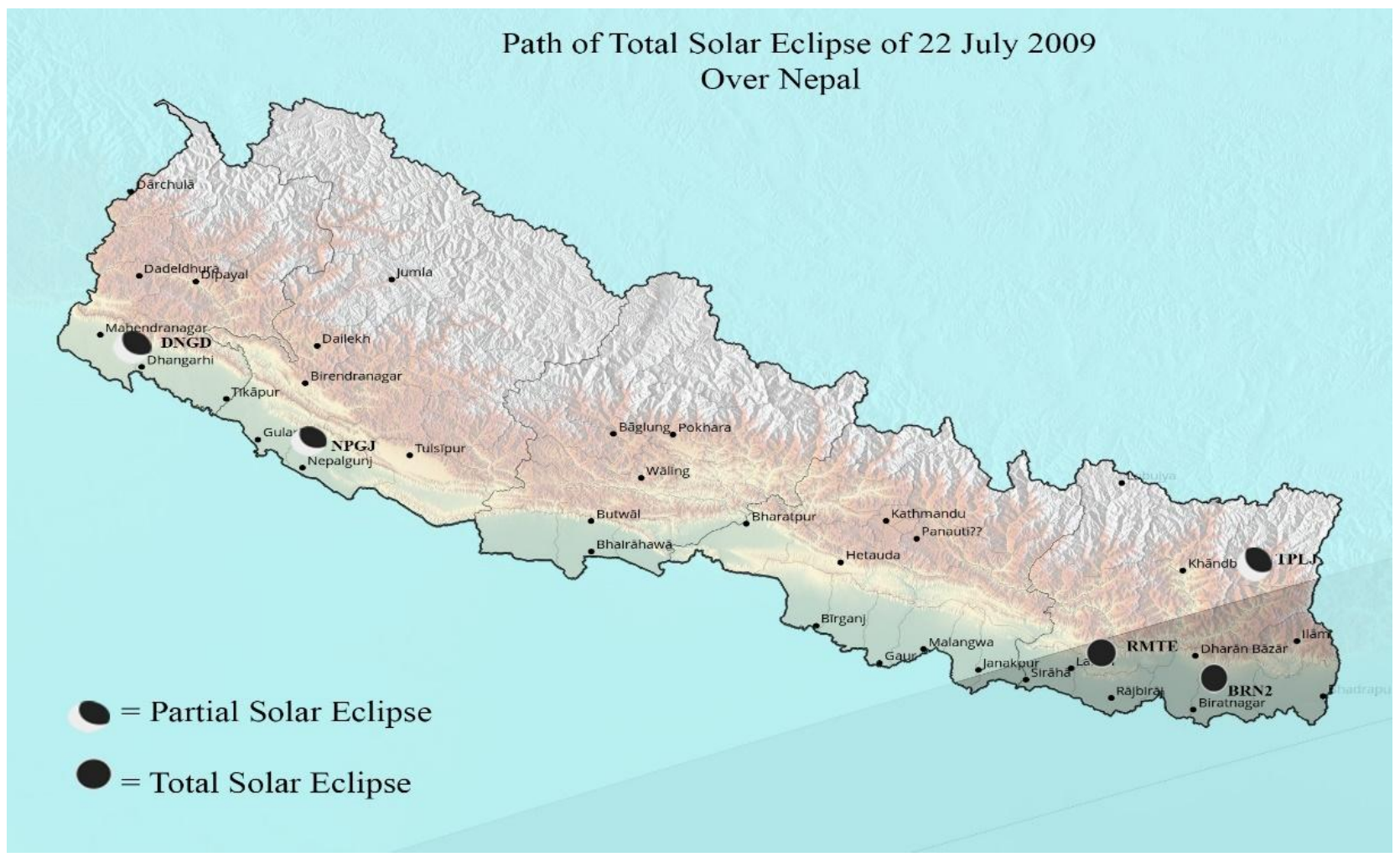

Fig. 1: The path of Total Solar Eclipse of 2009 July 22 over Nepal [14]. 
Table 1: Station information with the duration of solar eclipse

\begin{tabular}{lllllll}
\hline Stations & Code & Latitude & Longitude & Start (U.T) & Maximum (U.T) & End (U.T) \\
\hline Biratnagar (Total) & BRN2 & $26.5197^{\circ} \mathrm{N}$ & $87.2722^{\circ} \mathrm{E}$ & $12: 00 \mathrm{am}$ & $12: 57 \mathrm{am}$ & $02: 01 \mathrm{am}$ \\
Dhangadi (Partial) & DNGD & $28.7544^{\circ} \mathrm{N}$ & $80.5818^{\circ} \mathrm{E}$ & $12: 02 \mathrm{am}$ & $12: 57 \mathrm{am}$ & $02: 02 \mathrm{am}$ \\
Ramite (Total) & RMTE & $26.991^{\circ} \mathrm{N}$ & $86.5971^{\circ} \mathrm{E}$ & $12: 00 \mathrm{am}$ & $12: 57 \mathrm{am}$ & $02: 01 \mathrm{am}$ \\
Nepalganj (Partial) & NPGJ & $28.1172^{\circ} \mathrm{N}$ & $81.5953^{\circ} \mathrm{E}$ & $12: 02 \mathrm{am}$ & $12: 56 \mathrm{am}$ & $01: 57 \mathrm{am}$ \\
Taplejung (Partial) & TPLJ & $27.3522^{\circ} \mathrm{N}$ & $87.7098^{\circ} \mathrm{E}$ & $12: 00 \mathrm{am}$ & $12: 58 \mathrm{am}$ & $02: 02 \mathrm{am}$
\end{tabular}

\section{RESULT AND DISCUSSION}

3.1 Variation in TEC value during the eclipse period During the obscuration period, TEC variations in the pre-event, main event, and post-event have been studied for the complete and partial solar eclipse, as the effects can only be defined for very little time, as shown in Figures 2 and 3. In the pre-event and post-event as a whole, we observed a regular increase in TEC values. Instead, there was a decrease in TEC about 12:39 am (UT) in the main event after TEC values rose marginally over time. There was a decrease in TEC from pre-event to the main event by $2-5 \%$ by comparing the mean value of the pre-event, main event, and post-event, while a rise by $20-25 \%$ from main-event to post-event. And in each map, the maximum decrease in TEC obtained before the solar eclipse reaches its maximum impact is shown.
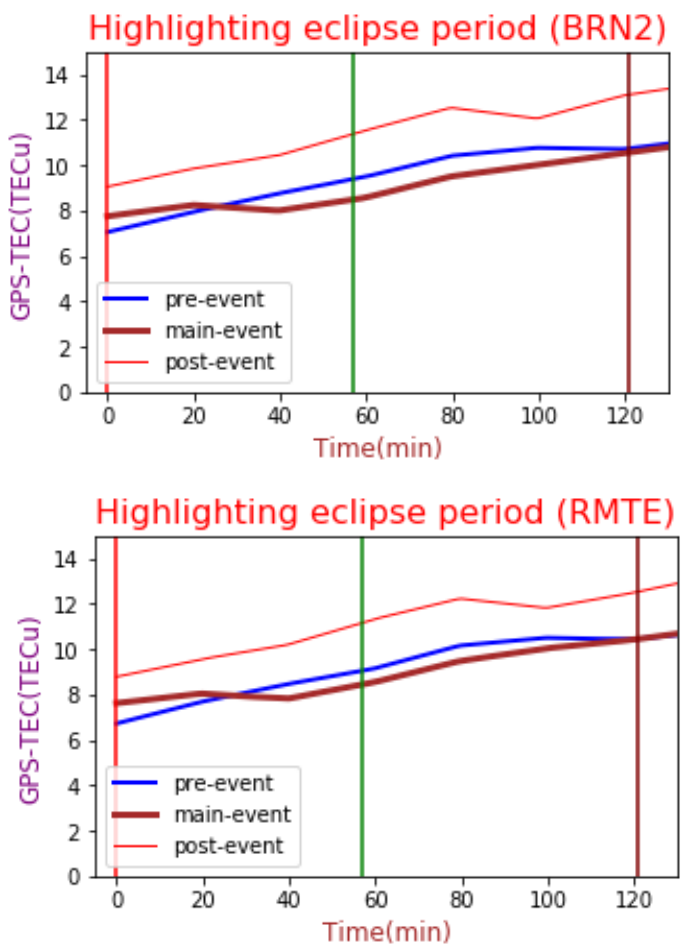

Fig. 2: TEC variation in BRN2 and RMTE stations (three vertical line shows the start time(red), maximum effect time(green), and the end time(maroon) respectively of the solar eclipse).

The minimum TEC obtained in the main event was higher than the minimum TEC of the preevent days in DNGD and NPGJ stations, which increased by $3-5 \%$ from pre-event to main-event and also by $26-29 \%$ to post-event. However, in the case of TPLJ station, a different form of the trend was found, which was the same as the stations in the totality area in which there was a $4.58 \%$ decrease in TEC value from the pre-event to the main event and an increase of $22.19 \%$ from the main event to the post-event. It should be remembered that the maximum decrease in TEC was achieved almost during the maximum impact of the eclipse at DNGD and NPGJ stations, but the maximum decrease in TEC at TPLJ stations was 19 minutes before the maximum effect of the solar 
eclipse as same as in totality area. The longitude was the common factor between them as they ranged from $86-88^{\circ} \mathrm{E}$ in which the minimum TEC
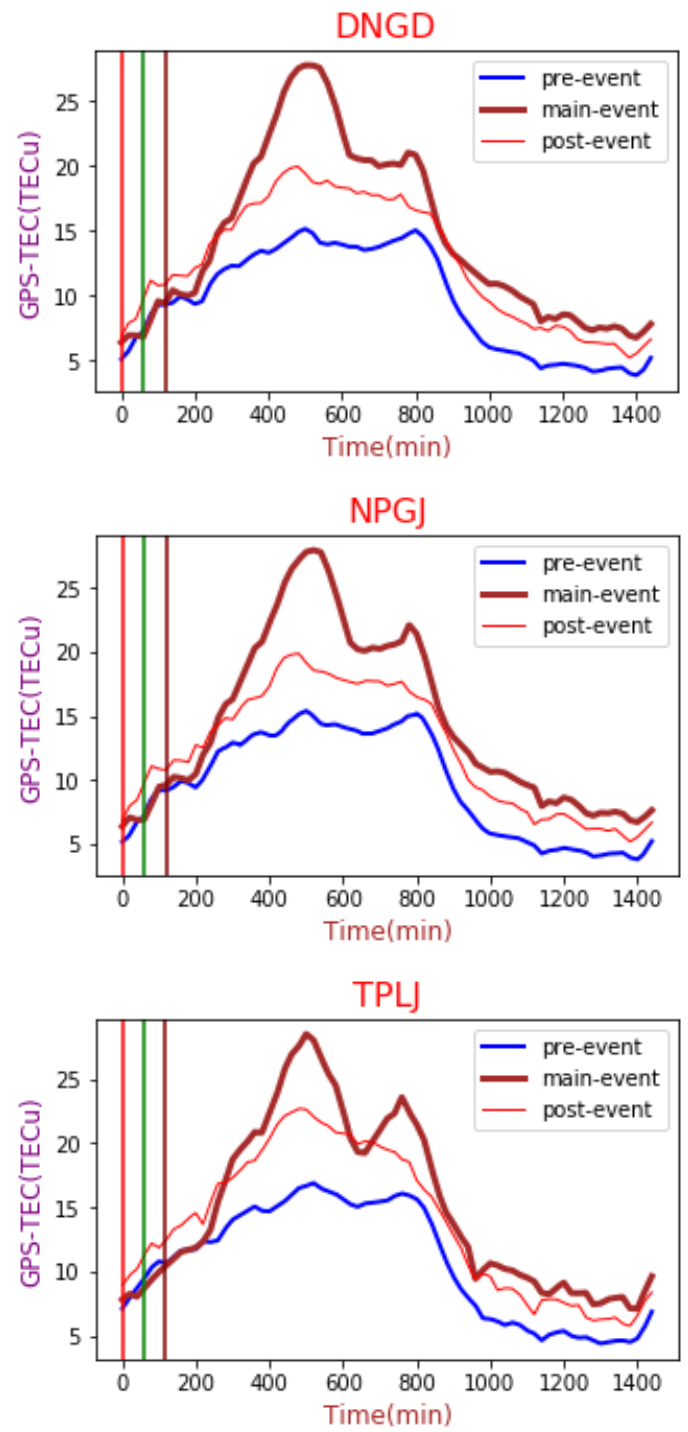

was obtained before achieving the maximum eclipse impact discussed in the following subsection.

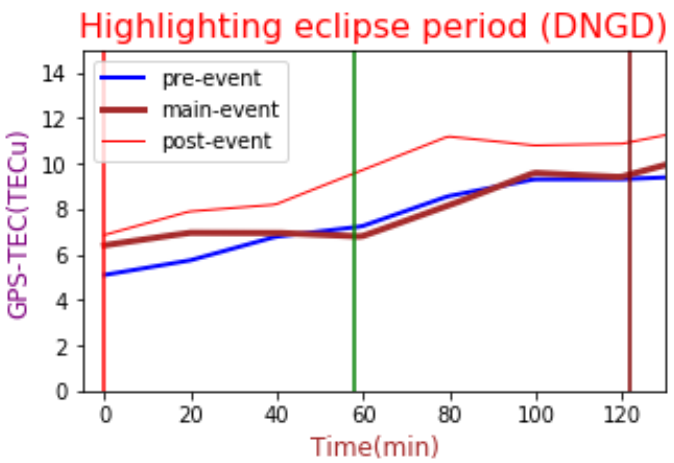

Highlighting eclipse period (NPGJ)

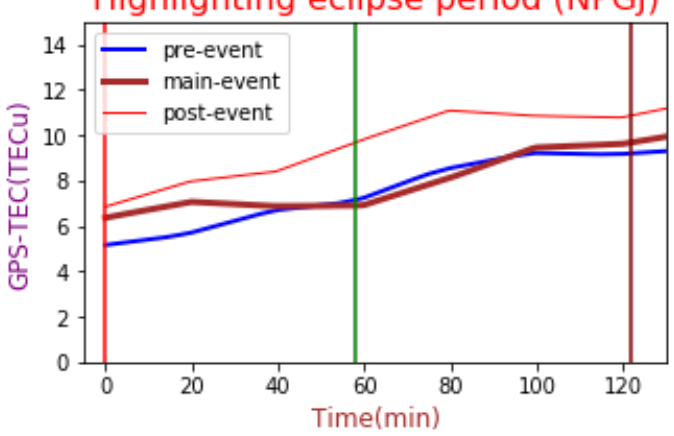

Highlighting eclipse period (TPLJ)

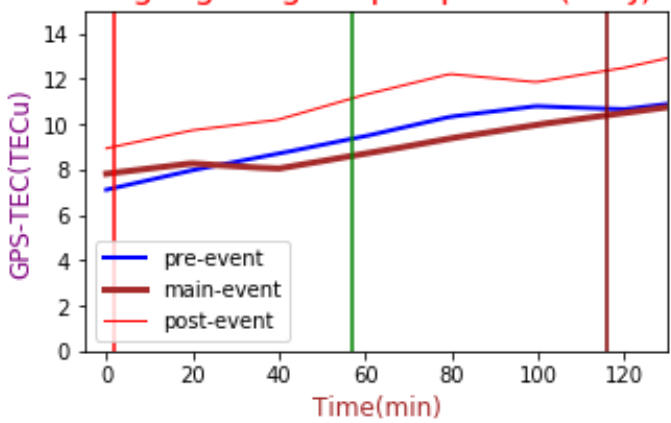

Fig 3: TEC variation in DNGD, NPGJ and TPLJ stations between pre, main and post-event during the partial solar eclipse.

\subsection{Effect of the solar eclipse on TEC variation with latitude and longitude}

The effect of the eclipse at different latitudes and longitudes was analyzed by comparing the minimum TEC during the solar eclipse duration for five stations with varying latitudes and longitudes as shown in Tables 2 and 3. In the totality and partiality area of the solar eclipse, two modes of variation were obtained. The latitude seemed to be directly proportional to the effect of the solar eclipse. Longitude, on the other hand, does not depend on the magnitude of the solar eclipse. Longitude was obtained for the influence of the solar eclipse to act inversely. The greater the longitude, the lower the solar eclipse effect, as shown in Figure 5. Longitude is connected to local time, and as shown in Figure 5, the time lag of TEC response to the eclipse increases with distance from the solar eclipse direction, which was responsible for the decrease in TEC. Krankowski et al., 2008, for the eclipse of 3 October 2005 [10], have also observed this behavior. The latitudinal and longitudinal dependence of the solar eclipse was also investigated by Ding et al., 2010; similar findings were obtained for the same occurrence on 22 July 2009 [2]. 
Table 2: Comparison of TEC with latitude

\begin{tabular}{|c|c|c|c|}
\hline Eclipse & Stations & Latitude $\left({ }^{\circ} \mathbf{N}\right)$ & $\begin{array}{l}\text { Minimum } \\
\text { TEC (TECU) }\end{array}$ \\
\hline \multirow[t]{2}{*}{ Total } & BRN2 & 26.5197 & 8.025 \\
\hline & RMTE & 26.991 & 7.815 \\
\hline \multirow[t]{3}{*}{ Partial } & TPLJ & 27.3522 & 8.035 \\
\hline & NPGJ & 28.1172 & 6.8675 \\
\hline & DNGD & 28.7544 & 6.79 \\
\hline
\end{tabular}

Table 3: Comparison of TEC with longitude

\begin{tabular}{lrr}
\hline Stations & Longitude $\left({ }^{\circ} \mathbf{E}\right)$ & \multicolumn{2}{c}{$\begin{array}{c}\text { Minimum TEC } \\
\text { (TECU) }\end{array}$} \\
\hline TPLJ & 87.7098 & 8.035 \\
BRN2 & 87.2722 & 8.025 \\
RMTE & 86.5971 & 7.815 \\
NPGJ & 81.5953 & 6.8675 \\
DNGD & 80.5818 & 6.79
\end{tabular}

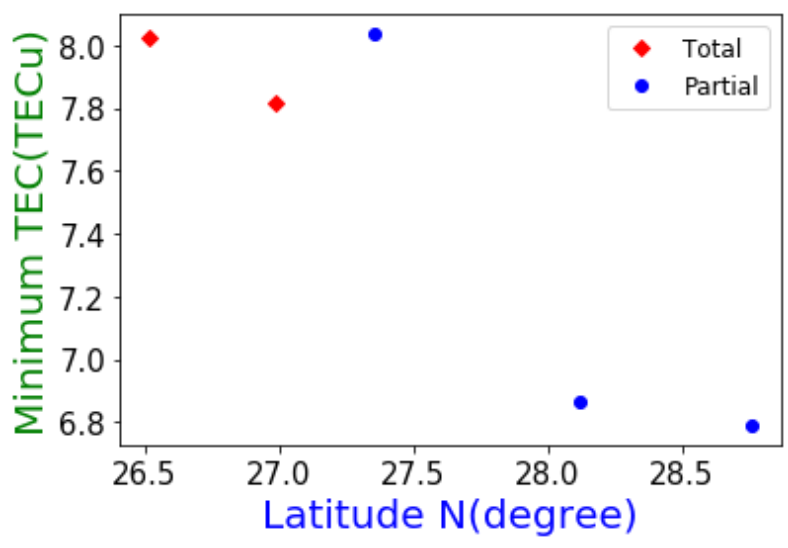

Fig. 4: Latitude versus Minimum TEC

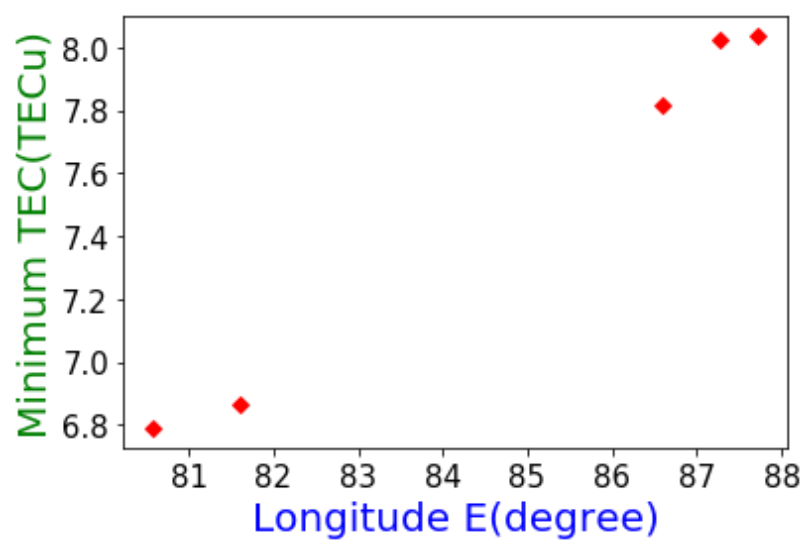

Fig. 5: Longitude versus Minimum TEC

\subsection{Variation of TEC value during the storm period}

To see the storm effect, the TEC variation was observed for an entire day. From pre-event to mainevent, the value of TEC increased by $36-51 \%$ (1013 TECU) and decreased by $8-23 \%$ (4-8 TECU) from main-event to post-event in all stations, as shown in Figures 2 and 3. In the overall analysis, in each station, the plot of each event was smooth and increased until 8/9 am (U.T), then decreased slightly after that point. For all the events at all the stations, we observed a large variation of GPS-TEC in the detailed study. Thus, the GPS-TEC continues to change from one event to another and the effect of the solar geomagnetic storm has been observed. The improvement in TEC was achieved due to the positive storm features of the ground-based GPS observer from 03:00 to 09:00-12:00 UT.

\section{CONCLUSION}

The impacts of the total solar eclipse of 22 July 2009 followed by a moderate storm on the TEC variation over Nepal are seen in the current analysis. The total solar eclipse was responsible for the brief decrease in TEC during the low latitude solar eclipse events, and the successive geomagnetic storm was responsible for the wholeday rise in TEC values. The lowest TEC was observed on the maximum path of the solar eclipse in all of Nepal. The time taken by the TEC to achieve the maximum reduction after the start of the eclipse is less than the recovery time and before 15-20 minutes of the maximum obscuration in the totality area, whereas in the partial region the maximum reduction achieved before the maximum impact of the eclipse ( 6 minutes) as the extreme reduction observed by the TEC during the solar eclipse is proportional to the magnitude of the eclipse.

The response of TEC to the solar eclipse depends on both latitude and longitude. The latitudinal component depends heavily on the magnitude of the solar eclipse, but the longitude does not. In the low latitude area, the impact of the solar eclipse on TEC variation is lower. This validates the finding of Le et al. (2009), Chakraborty et al. (2015), Kumar et al. (2013), and Srigutomo et al. (2019) which indicates that the local time dependence of the TEC response is closely related to the local time variation of the background atmospheric density affecting the electron loss efficiency in the ionosphere. The longitude and the effect of the solar eclipse are inversely proportional to each 
other. This was also recorded by Krankowski et al., 2008; and Ding et al., 2010. The result shows that ground-based GPS observations could correctly replicate the TEC during the eclipse/storm period.

\section{ACKNOWLEDGMENTS}

We remember the Workshop on Space Weather and Upper Atmosphere Physics (WSWUAP) conducted at Amrit Campus in collaboration with ICTP to provide calibration technology software. We are very grateful to the UNAVCO (University Government Consortium) data center for GPS data over the Nepalese stations.

\section{CONFLICTS OF INTEREST}

There is no conflict between the author's side.

\section{EDITOR'S NOTE}

This manuscript was submitted to Association of Nepali Physicists in America (ANPA) Conference 2020 for publication in special issue of Journal of Nepal Physical Society.

\section{REFERENCES}

[1] Amabayo, E. B.; Anguma, S. K. and Jurua, E. Tracking the Ionospheric Response to the Solar Eclipse of November 03, 2013. Int. J. Atmos. Sci., 2014: 1-11 (2014).

[2] Ding, F.; Wan, W.; Ning, B.; Liu, L.; Le, H.; Xu, G.; Wang, M.; Li, G.; Chen, Y.; Ren, Z., et al. GPS TEC response to the 22 July 2009 total solar eclipse in East Asia, J. Geophys. Res., 115: A07308 (2010).

[3] Alizadeh, M. M.; Schuh, H.; Zare, S.; Miandehi, S. S. and Tsai, L. Remote sensing ionospheric variations due to solar eclipse, using GNSS observations, Geod. Geodyn., 306: (2019).

[4] Le, H.; Liu, L.; Yue, X.; Wan, W. and Ning, B. Latitudinal dependence of the ionospheric response to solar eclipses, J. Geophys. Res., 114: 148-160 (2009).

[5] Chakraborty, M.; Kumar, S.; De, B. K. and Guha, A. Effects of geomagnetic storm on low latitude ionospheric total electron content: A case study from Indian sector, J. Earth Syst. Sci., 124: 11151126 (2015).

[6] Atici, R.; Aytas, A. and Sagir, S. The effect of solar and geomagnetic parameters on total electron content over Ankara, turkey, $A D V$ SPACE RES, 65: 2158-2166 (2020).

[7] Rastogi, R. G. and Klobuchar, J. A. Ionospheric Electron Content within the Equatorial F2 Layer Anomaly Belts. Journal of Geophysical
Research: Space Physics, 95: 19045-19052 (1990).

[8] Adekoya, B. J.; Chukwuma, V. U. and Reinisch, B. W. Ionospheric vertical plasma drift and electron density response during total solar eclipses at equatorial/low latitude, J. Geophys. Res. Space Physics, 120: 8066-8084 (2015).

[9] Salah, J. E.; Oliver, W. L.; Foster, J. C. and Holt, J. M. Observations of the May 30, 1984, Annular Solar Eclipse at Millstone Hill, J. Geophys. Res., 91(A2): 1651-1660 (1986).

[10] Kumar, S.; Singh A. K. and Singh, R. P. Ionospheric response to total solar eclipse of 22 July 2009 in different Indian regions, Ann. Geophys., 31: 1549-1558 (2013).

[11] Srigutomo, W.; Singarimbum, A.; Meutia, W.; Djaja, I. G. P. F. S.; Muslim, B. and Abadi, P. Decrease of total electron content during the 9 March 2016 total solar eclipse observed at low latitude stations, Indonesia, Ann. Geophys. Discuss. (2019).

[12] Krankowski, A.; Shagimuratov, I. I.; Baran, L. W. and Yakimova, G. A. The effect of total solar eclipse of October 3, 2005, on the total electron content over Europe, ADV SPACE RES, 41: 628638 (2008).

[13] Ya'acob, N.; Abdullah, M. and Ismail, M. GPS Total Electron Content (TEC) Prediction at Ionosphere Layer over the Equatorial Region, Trends Telecommun. Technol., 23: 484-508 (2010)

[14] https://www.solar-eclipse.info/eclipse/images/ countrymap_political_2009-0722_NP.jpg (Viewed on May 21, 2020). 